\title{
Unconditional types of inference and logical knowledge
}

\author{
Tipos incondicionais de inferência e \\ o conhecimento lógico
}

*Luis Rosa

\begin{abstract}
In this paper I address the question 'How is knowledge of logical truths possible'. The sought-after explanation should be (ideally) independent of what the true story about logical truth is. In particular, I try to account for the epistemic warrant that is conferred upon logical beliefs when they are neither inferred from other beliefs nor grounded on empirical evidence or testimony. The need for such an account is motivated by the apparent failure of the notions ofanalyticity on the one hand and intuition on the other in addressing the relevant question. I end up defending an account according to which warranted logical beliefs can be grounded on pure reasoning: they can be inferentially formed on the basis of pieces of suppositional reasoning.
\end{abstract}

Keywords: Logical knowledge. Inference. Logical truths. Epistemic warrant. Pure reasoning.

Resumo: No presente artigo, trato da questão 'Como o conhecimento de verdades lógicas é possível?'. A explicação que procuro deveria (idealmente) ser independente de qual é a verdadeira teoria sobre verdades lógicas. Mais especificamente, tento explicar a natureza do status epistêmico conferido sob crenças em proposições lógicas quando tais crenças não são inferidas de outras crenças, ou sequer baseadas em evidência empírica ou testemunho. A necessidade de tal teoria é motivada pela aparente falha das noções de analiticidade e intuição em responder à questão mencionada. Termino defendendo uma teoria de acordo com a qual crenças lógicas com status epistêmico positivo podem ser embasadas em puro raciocínio: elas podem ser formadas inferencialmente com base em raciocínio envolvendo suposições.

Palavras-chave: Conhecimento lógico. Inferência. Verdades lógicas. Status epistêmico; puro raciocínio.

\footnotetext{
* Luis Rosa is Alexander von Humboldt Fellow at Ludwig-Maximilians-Universität München. Fakultät für Philosophie, Wissenschaftstheorie und Religionswissenschaft. Munich Center for Mathematical Philosophy Geschwister-Scholl-Platz 1 D-80539 München. <Luis.Rosa@lrz.uni-muenchen.de>.
} 
Consider logical claims such as Either the president is in her office or she is not, If Lucy is a environmentalist lawyer then some environmentalists are lawyers, and It is not the case that: the water is contaminated and it is not contaminated. There are many ways in which one could explain what is 'logical' about these claims, e.g. that they are logically necessary, that they are theorems of certain logical systems, etc. But how is knowledge of (the truth of) these claims possible? At first glance, it would appear that the answer to that question should be intimately connected to the question: what makes those logical claims true?

Consider for example a version of psychologism about logic-one according to which what makes logical claims true is (loosely speaking) the architecture of our own minds. It is true that Either the president is in her office or she is not because it is not even possible for us to conceive of the possibility that The president is in her office and she is not in her office at the same time. One would then address the epistemological question thus: logical knowledge is possible because we can have introspective knowledge of the ways in which we can and cannot think (one is reminded here of Boole's view of logic as an investigation into "... the fundamental laws of those operations of the mind by which reasoning is performed" (1854, p. 1)). Or suppose that platonic realism about logic-roughly the view that what makes logical claims true is the way in which certain mind-independent forms are arranged or constitutedis true. Then how can we ever come to know about the ways in which those abstracta are arranged and constituted? Echoing Benacerraf's (1973) worry concerning the relationship between the semantics and the epistemology of mathematics, one might then point out that, since it is very difficult to see how we could causally interact with those abstract objects (they are not in space and time), it is therefore very difficult to see how we could have any knowledge about them.

In the case of psychologism, the thesis that logical truths are in some sense 'mental' apparently makes the epistemologist's life easier: it is not difficult to see how we can attain logical knowledge because it is not difficult to see that we can have introspective access to our own ways of thinking. In the case of platonic realism, the thesis that logical truths are about mind-independent abstracta apparently makes the epistemologist's life harder: how can we have knowledge about something that we cannot causally interact with? Either way, there seems to be an intimate connection between the epistemological question'How is knowledge of logical truths possible?'-and the partly semantic/ partly metaphysical question-'What makes logical truths true?'. 
But I think that the impression that there is such an intimate connection here is misleading. Of course, both the logical positivists and also some contemporary defenders of the idea of analyticity would agree with me here: for them, logical knowledge is somehow based on linguistic competence or understanding. And that may hold good whatever the true story about logical truth is. But as it will be seen below there are also good reasons to think that logical positivists and friends of analyticity in general are wrong. So what I will do here is: I will sketch an account of how logical knowledge is possible that holds good whatever the true story about logical truth is-but that account does not rely on the notion of analyticity.

More specifically, I will give an answer to the following question: how can we be epistemically warranted in taking logical claims to be the case? This should be seen as only part of the answer to the initial question about the possibility of logical knowledge: warrant is necessary but not sufficient for knowledge.

Before I present the account, however, let me be more precise about what I mean by 'epistemic warrant'. There are at least two different ways in which one might engage in epistemic warrant-talk: (i) by making reference to the fact that a subject has good reasons or evidence to believe something, and (ii) by making reference to the fact that a subject's belief exhibits certain properties (not necessarily internally accessible ones) that make it highly likely that the subject's belief is true. As an example of (i), we might say that Lucy is warranted in believing that Tom has a prejudice against women because she knows that Tom has a nasty attitude towards women, that Tom says that women are less intelligent, etc. Her evidence is good evidence to believe that Tom has a prejudice against women, and she believes that to be so on the basis of that evidence. As an example of (ii), we might say that Lucy is warranted in believing that The first note that was played on the piano and the second one are different ones. She does so after hearing a sequence of a $\mathrm{C}$ and a $\mathrm{G}$ being played on the piano-Lucy has a good ear for distinguishing those notes/chords. Almost invariably, when two distinct notes are played on the piano, she captures the difference. She is sensitive to different sound waves, and forms beliefs accordingly.

In the former case, we ascribe warrant in the sense that the subject believes something on the basis of good evidence or reasons. Call that type of warrant 'internal warrant', for it has to do with what is available to the subject herself to believe that something is true. In the latter case, we ascribe warrant in the sense that the subject's belief is reliably formed: the process by means of which the belief was formed is truth-conducive. Call that type of warrant 'external warrant' (no 
implication that internal and external warrant are disjoint properties intended).

Now these are two different questions:

(1) How can one be internally warranted in believing logical claims?

(2) How can one be externally warranted in believing logical claims?

Question (1) concerns the types of reasons on the basis of which one could believe that Either the president is in her office or she is not, that If Lucy is a environmentalist lawyer then some environmentalists are lawyers, etc. The question here is: what counts as a good reason to believe those things? Question (2) concerns the types of reliable processes that would output logical beliefs, however. The question here is: what cognitive processes could lead one to form those logical beliefs in a reliable, truth-conducive way?

Of course, there is a way in which both questions can be answered at once: one can be both internally and externally warranted in believing those logical claims by reliably inferring them from other things one already knows to be the case. In that case, the subject would not only hold a logical belief on the basis of good reasons-her logical belief is also the output of a reliable belief-forming process: a process of inference. But it is highly implausible that we hold all our logical beliefs as a result of inference from previously held beliefs. I did not infer my belief that It is not the case that 49 is a prime and not a prime from anything else I know. Its epistemic status does not 'come from' the epistemic status of other beliefs of mine. What then? Now we have two other questions in front of us:

(3) How can one be internally warranted in believing logical claims if not by means of inference from other beliefs?

(4) How can one be externally warranted in believing logical claims if not by means inference from other beliefs?

I do not think that the sense in which I can be warranted in believing a logical claim without inferring it from other beliefs is the internal sense. Internal warrant requires reasons or evidence, and it is hard to see what could play the role of reasons or evidence but beliefs or propositions (which in any case must be in the subject's doxastic reach). And this is of course related to the problem of regress of reasons, which in any case is not the topic of this paper. So the type of epistemic warrant I am going to deal with here is that of external warrant. I.e. my question is (4), and not (3). (From now on, whenever I use the term 'warrant' I just 
mean external warrant.) The answer to question (4) should be seen as part of the answer to the question: 'How is knowledge of logical truths possible?', for knowledge arguably requires external warrant.

Now, it seems not only that we can be warranted in believing logical claims to be true without inferring them from other beliefs-it also appears that we can be so warranted independently of experience. Or: we can be a priori warranted in taking them to be true. Of course, experience is needed for subjects to even understand the relevant claims, to acquire the relevant concepts, etc. But that observation is more trivial, for its truth holds across-the-board (for all beliefs), and that is not the sense in which experience confers epistemic warrant. So what I mean is: a logical belief can be warranted even when it is not grounded or based on empirical evidence. How so?

\section{2}

Canonically, there has been two ways-not necessarily incompatible ones-of addressing this issue: (I) by means of the idea that intuition, or rational insight, is a primary source of warrant for logical beliefs, (U) by means of the idea that understanding is a primary source of warrant for those beliefs. Perhaps proposal (I) is best understood as a thesis concerning internal warrant. It is very difficult to account for external warrant using that proposal, for there is not even a sketch of how intuition could lead the subject to form logical beliefs (or beliefs in general) in a reliable, truth-conducive way. What are exactly the properties of the process of believing on the basis of intuition that are responsible for its reliability? One might suggest: intuition is a state by means of which the subject can just 'see' that some things are necessarily true. Since one can then construe the truth-conditions for one to 'see' things in this sense by requiring intuition to be a factive cognitive state, one can thereby get the result that intuition is reliable. But that is more like explaining how and why a coffee machine makes good coffee by pointing out that it does make good coffee. What we are not told is how intuition connects us with the ways things are. Furthermore, it is a well-known criticism that the very notion of intuition or rational insight is quite obscure (see e.g. Devitt 2014 for a similar objection).

An old doctrine of type (U) is the one according to which logical claims are 'analytic'. There are at least two general notions of analyticity (see Boghossian 1996). The first one is the notion of metaphysical analyticity: it roughly says that analytic truths are true purely in virtue of meaning. E.g., a claim of the form $(\varphi \vee \neg \varphi)$ is true because ' $\neg$ ' reverses the truthvalue of the negated claim and ' $\vee$ ' maps any two claims into the True 
whenever at least one of them is mapped into the True. The second one is the notion of epistemological analyticity. A claim is analytic in this sense when accepting it/being disposed to accept it is constitutive of understanding certain terms that figure in it. E.g. one might suggest that it is constitutive of understanding negation and disjunction that one accepts/is disposed to accept claims of the form $(\varphi \vee \neg \varphi)$. A person who fails to accept or to be disposed to accept claims of that form thereby counts as failing to understand either disjunction or negation (or both).

Either way, the idea would be that understanding is the source of epistemic status of logical beliefs. But both ideas have been shown to be deeply problematic in the contemporary literature. And this is not just about Quine's (1951) classical attack on the very distinction between analytic and synthetic truths (that we go round and round trying to make sense of the notion of analyticity by means of other notions, e.g. that of synonymy). Against the metaphysical notion of analyticity, it has been argued that no good sense is to be made of the idea of being true only in virtue of meaning - the truth of all claims depends on how things are (see Boghossian 1996), or: every proposition puts constraints on the ways the world could be, no matter how 'trivial' those constraints appear to be (see Williamson 2007, Ch. 3). Against the epistemological notion it has been argued, also by Williamson (2007, Ch. 4), that it is perfectly possible (and sometimes that is actually the case) that one may fail to accept/ be disposed to accept purportedly analytic claims without failing to understand the relevant notions that figure in it. E.g. the deviant logician who rejects instances of excluded-middle with vague predicates is as competent a user of disjunction and negation as the classical logician is. Deviant logicians use natural language in general, and those terms in particular, in the same way English-speakers in general do. The peripheric differences that the deviant logician exhibits (as compared to the classical logician) are manifestations of theoretical differences, not of linguistic incompetence.

So epistemological analyticity accounts (like the one that defended by Boghossian) are committed to a problematic theory of the understanding of logical constants. Furthermore, the epistemological analyticity account--when conceived as an account of external warrant--is unsatisfactory, insofar as it does not really say what is the type of cognitive process that could be responsible for outputting logical beliefs. As a consequence, we cannot assess any process-type reliability either. We are told that accepting certain logical claims is constitutive of being a competent user of logical constants, but no details are given about the properties of the relevant belief-forming processes. 
And even if we bracket that issue, a problem still remains. What if the type of claim that the subject needs to be disposed to accept in order to count as understanding the relevant logical constants is only contingently true? E.g., perhaps the only instances of excluded-middle that are logical truths are the ones that involve non-vague predicates (like Either 49 is prime or 49 is not prime), and perhaps the instances that do involve vague predicates (like Either John is bald or he is not bald) all lack truth-value. In principle, there is nothing in the semantic account that excludes that possibility. So the defender of the semantic account perhaps would like to add that the claim that the subject needs to be disposed to accept as a pre-condition for understanding the relevant logical concepts is always true (or necessarily true). But in order to account for the fact that this or that logical belief in particular is warranted, she would then need to address thorny issues in semantics and metaphysics (e.g. she would need to argue against certain theories of vagueness: the ones according to which there are counterexamples to excluded-middle). That is quite a burden for an epistemology of logic to carry.

So, to sum it up: An account of how we can be externally warranted in holding logical beliefs is needed, as it should be part of the answer to the question: 'How is knowledge of logical truths possible?'. Such an account-or so I claim-can be given independently of what is the true story about logical truths (so the epistemology of logic does not need to wait until we have the correct theory of logical truths). Analyticity accounts purport to do that, but they are problematic in a number of ways. So we would need an alternative account of the source of warrant for logical beliefs. I will flesh out such an account below.

\section{3}

Roughly put, my thesis is that we can pull logical knowledge out of our own inferential abilities. The idea is that reasoning can be a source of warrant, not only a means of transmitting warrant from believed premises to conclusions (see Balcerak Jackson \& Balcerak Jackson 2013 for a defense of a similar claim, and also Dogramaci 2016).

Let me give some examples:

Example 1. I hypothesize that Judy is a hippie economist. Under that assumption, I derive the (hypothetical) conclusion that Some hippies are economists. On the basis of that piece of suppositional reasoning, I finally conclude that If Judy is a hippie economist, then some hippies are economists.

Veritas | Porto Alegre, v. 61, n. 2, maio-ago. 2016, p. 350-362 
Example 2. I hypothesize that Aliens exist. Under that assumption, I derive the (hypothetical) conclusion that It is not the case that aliens do not exist. On the basis of that piece of suppositional reasoning, I conclude that It is not the case that: aliens exist and they do not exist.

These examples should be familiar to anyone who had his or her bit of proof-theory. But there is no reason why they should occur only in the logic class, and no good reason to think that in order to perform these inferences one needs to use derivation rules of a certain sort. They may perfectly well be ordinary pieces of reasoning, thinking processes that human beings in general can go through. (Compare to garden-variety cases of inference on the basis of grounding beliefs: that I inferred that Don is a detective from my belief that Don is a good detective does not mean that I have applied the rule of conjunction-elimination. I'm just a reasoner, not necessarily a logician.) And it turns out that the beliefs that those processes output have exactly the types of logical claims I mentioned at the beginning of this paper as their content.

Here is what these reasoning processes have in common: their inferential beliefs are not based on other beliefs that are held by the subject; they are rather grounded on pieces of suppositional reasoning. They surely are types of inference-but unconditional ones, meaning that their conclusions do not depend on any believed premises (in contrast to conditional types of inference, whose conclusions are based on believed premises). One clearly makes assumptions or hypotheses here, but those assumptions need not be maintained as beliefs in order for one to reach the relevant conclusions. Furthermore, it would seem that these inferential processes qualify as sources of a priori warrant: their output beliefs are not grounded on empirical evidence either. So by using these types of inferential processes one could come to know logical truths from the armchair.

In order to make sure that logical beliefs can indeed be externally warranted when they are produced by unconditional ways of inferring of the relevant kind, however, a satisfiable condition is needed such that, if it is satisfied, then it follows that a certain unconditional way of inferring that outputs a logical belief is reliable. And that is precisely what I am going to do next. Before I do that, however, I need to sharpen my terminology/notation.

Let ' $\Gamma \Rightarrow B \varphi$ ' represent a type of inference, or a way of inferring from certain grounds $\Gamma$ to a belief in a content of type $\varphi$. The symbol 
' $\Rightarrow$ ' is just supposed to represent a reasoned state-transition, and it is not to be confused with a conditional or any other type of sentential connective. ' $\Gamma \Rightarrow B \varphi$ ' is not a sentence-if anything, it behaves more like a definite description of a way of inferring. When the type of inference is of a conditional type, the ground $\Gamma$ is just a set of beliefs, so that representations of these types of inference will have the general form:

$$
\left\{B \psi_{1}, \ldots, B \psi_{n}\right\} \Rightarrow B \varphi
$$

When the type of inference is of an unconditional type, however, the ground $\Gamma$ is itself a reasoned state-transition. So in the simplest cases of unconditional inference we will have something like:

$$
[A \psi \Rightarrow A \sigma] \Rightarrow B \varphi
$$

where $A$ represents the attitude of assuming something to be the case (conditional on other assumptions or otherwise) and $A \psi \Rightarrow A \sigma$ therefore represents a piece of suppositional reasoning that goes from the assumption that $\psi$ to the conditionally held conclusion that $\sigma$.

There are even more complex unconditional types of inference, involving more than one piece of suppositional reasoning and/or pieces of suppositional reasoning. Taking these in consideration, a more inclusive general form would be something like:

$$
\left[\left[A \psi_{1} \ldots \mathrm{A} \psi_{n} \Rightarrow A \sigma_{1}\right],\left[A \rho_{1} \ldots A \rho_{n} \Rightarrow A \sigma_{2}\right] \ldots\left[A \chi_{1} \ldots A \chi_{n} \Rightarrow A \sigma_{n}\right]\right] \Rightarrow B \varphi
$$

And there may of course be types of inference whose grounds are partly constituted by beliefs and partly by pieces of suppositional reasoning.

So, consider again the examples of unconditional inference that were given above. The way of inferring instantiated in the first example might be described as follows: the subject assumes a claim of type $\alpha$ is a $\Phi$ and a $\Psi$ to be the case, derives a conclusion of type Some $\Phi_{s}$ are $\Psi_{s}$ under that assumption, and then she forms a belief toward a claim of type If $\alpha$ is a $\Phi$ and a $\Psi$ then some $\Phi s$ are $\Psi$ s on the basis of that piece of suppositional reasoning. Even more schematically:

$[A(\alpha$ is a $\Phi$ and a $\Psi) \Rightarrow A($ Some $\Phi$ s are $\Psi$ s $)] \Rightarrow$

$\Rightarrow B\left(\right.$ If $\alpha$ is a $\Phi$ and a $\Psi$ then some $\Phi$ s are $\left.\Psi_{S}\right)$

And the way of inferring instantiated in the second example might be described as follows: the subject assumes a claim of type $\varphi$ to be 
the case, derives a conclusion of type not-not- $\varphi$ under that assumption, and then she forms a belief toward a claim of type not- $(\varphi$ and not- $\varphi)$ on the basis of that piece of suppositional reasoning. Or even more schematically:

$$
[A \varphi \Rightarrow A(\text { not-not- } \varphi)] \Rightarrow B(\text { not }-(\varphi \text { and not }-\varphi))
$$

Of course, the types of claims mentioned in the description of those ways of inferring need not be the logical forms of theirs instances (in which case their set of tokens would have an infinite size), as these examples might suggest. E.g. in the first example, perhaps (1) only terms with a denotation count as instances of $\alpha$, in which case Pegasus is a horse and it is beautiful is not really a token of $\alpha$ is a $\Phi$ and a $\Psi$; or perhaps (2) only terms whose referents are concrete things (as opposed to abstract and fictional ones) count as instances of $\alpha$, in which case 2 is a natural number and also a prime number is not really a token of $\alpha$ is a $\Phi$ and a $\Psi$. That is to say: perhaps the relevant types of claims or content-types (relevant to describe the way in which the reasoner is reasoning, as manifested in the inferences she would/would not perform as we vary the specific contents of her thought) are not just their grammatical shapes, for they may also be individuated through their semantic properties. And this means that the same particular inference may be an instantiation of many different types of inference.

This is reminiscent of the 'generality problem' for reliabilism. Roughly put, this is the problem that process-types are underdetermined by their tokens: there are many process-types a particular process may be a token of. Depending on which process-type is instantiated in each particular case, the belief that the actual process outputs may or may not be justified-at least according to reliabilism about justification (see Goldman 1979, p. 12 for the original formulation of the problem). So what is the relevant process-type in each particular case? If there is no principled way of telling that, how can we be entitled to claim that such-and-such a belief is justified?

But this won't be a problem for my proposal. For I am not concerned with showing that such-and-such a logical belief is justified (or, in my case, externally warranted), only with showing that it is so much as possible for a logical belief that was not inferred from other beliefs to be non-empirically warranted. In order to make that point, I don't need to come up with a way of determining which process-types are instantiated in which cases. What I need to establish is just that there are reliable processes of unconditional inference that would output the relevant logical beliefs. 
I will now present a condition whose satisfaction entails that there are processes like that. The relevant condition quantifies over tokens of content-types, and it requires all of them to satisfy certain alethic properties.

Before establishing the condition, however, let me briefly say why it is necessary to mention content-types here. The reason is that reliability is not a matter of success in one particular case only. Consider for example conditional inference, or inference on the basis of grounding beliefs. One might think that my inference that Stephane likes me on the basis of my belief that Stephane likes logicians and I am a logician is a reliable one-if only because the latter claim entails the former one. But the fact is just that I am a selfish bastard, and I would believe that Stephane likes me no matter what claim about Stephane was given to me as input. E.g., if my grounding belief were Stephane is a linguist, instead of Stephane likes logicians and I am a logician, I would still form the belief that Stephane likes me. Only I got lucky in the actual situation, where the content of my input-belief actually entails the content of my output-belief. But in many other instances in which I would instantiate the same type of process I am actually instantiating, that would not be the case.

So what is needed for reliability is a truth-connection between the content-types I am reasoning with. That there is such a truth-connection among content-types can be seen by the fact that all its tokens satisfy it, or perhaps that most of its tokens satisfy it. Let $t_{k}$ (for $k>0$ ) be a typetoken mapping, or a function that maps a content-type into one of its tokens. If you change $k$, the same content-type is mapped into a different token. E.g., maybe $t_{1}(\varphi)=p$ whereas $t_{2}(\varphi)=q$, where $\varphi$ is a content-type and $p$ and $q$ are two different tokens of that type.

Now we can quantify over tokens of content-types and require them to satisfy the relevant truth-connection. E.g., in the case of conditional inference, the following would undoubtedly be a reliability-entailing condition for a type of inference $\left\{B \psi_{1}, \ldots, B \psi_{n}\right\} \Rightarrow B \varphi$ :

(CR) For all $k$, necessarily: if $t_{k}\left(\psi_{1}\right), \ldots, t_{k}\left(\psi_{\mathrm{n}}\right)$ are all true, then $t_{k}(\varphi)$ is true.

Of course, there may be reliable types of conditional inference that do not satisfy (CR), if only because there may be reliable types of conditional inference such that the truth of their conclusions is only probably true given the truth of their premises. But (CR) is not supposed to be a necessary condition for reliability either-it is just an illustration of a condition whose satisfaction entails that there are reliable conditional 
types of inference. What we need now is an analogous condition for unconditional types of inference. What condition would that be?

One might suggest that the following would do as a reliabilityentailing condition for an unconditional type of inference $[A \psi \Rightarrow A \sigma] \Rightarrow B \varphi$ :

(UR') For all $k$, necessarily:

if $t_{k}(\sigma)$ is true whenever $t_{k}(\psi)$ is true, then $t_{k}(\varphi)$ is true.

But that actually does not follow. Here is the problem. Reliable processes should at the very least tend to output more true beliefs than false ones. But there are types of inference whose content-types satisfy (UR') that would not ever produce true beliefs, only false ones. The following type of inference will do as an example:

$$
[A(\varphi \rightarrow \varphi) \Rightarrow A \neg(\varphi \rightarrow \varphi)] \Rightarrow B \neg(\varphi \rightarrow \varphi)
$$

If the conditional ' $\rightarrow$ ' behaves semantically like a material conditionaland let us assume it does so, for the sake of the argument--then $t_{k}(\varphi \rightarrow \varphi)$ is necessarily true and $t_{k}(\neg(\varphi \rightarrow \varphi))$ is necessarily false, for any $k$. Now, assuming that the conditionals '--- whenever _ ' and 'if --- then_.' also behave like material conditionals, it follows that ' $t_{k}(\varphi \rightarrow \varphi)$ is true whenever $t_{k}(\neg(\varphi \rightarrow \varphi))$ is true' is necessarily false, and so 'if $t_{k}(\varphi \rightarrow \varphi)$ is true whenever $t_{k}(\neg(\varphi \rightarrow \varphi))$ is true, then $t_{k}(\neg(\varphi \rightarrow \varphi))$ is true' is necessarily true. But surely that type of inference is not reliable, for whenever one reasons in that way one ends up forming a false belief.

There is a handy solution to that problem, however:

(UR) For all $k$, necessarily: (1) if $t_{k}(\sigma)$ is true whenever $t_{k}(\psi)$ is true, then $t_{k}(\varphi)$ is true, and (2) $t_{k}(\sigma)$ is true whenever $t_{k}(\psi)$ is true.

Now the additional condition (2) eliminates the possibility that the big conditional 'if $t_{k}(\varphi \rightarrow \varphi)$ is true whenever $t_{k}(\neg(\varphi \rightarrow \varphi))$ is true, then $t_{k}(\neg(\varphi \rightarrow \varphi))$ is true' is trivially true-because it eliminates the possibility that its antecedent is necessarily false. In fact, an unconditional type of inference whose content-types satisfy (UR) are maximally reliable, because all beliefs they output are necessarily true.

So that assures us that there are reliable unconditional types of inference. And, of course, they may output logical beliefs (e.g. the content-types in Examples 1 and 2 may certainly satisfy (UR)). So that would account for the possibility of there being externally warranted logical beliefs that were neither inferred from other warranted beliefs nor grounded on empirical evidence. Furthermore, notice that this account fits the bill mentioned at the beginning of this paper: we do not need to say anything about what makes logical truths true here. We only need to mention certain types of inference whose content-types have certain 
alethic properties. Reliability lies in the way in which we reason-not in how we get 'connected' to truth-makers of logical truths.

\section{Conclusion}

In this paper I made certain moves toward an account of logical knowledge that may hold good whatever the true story about logical truth is. Benacerraf-ish worries about logical knowledge do not even get off the ground here. Furthermore, that account makes no use of the problematic notion of analyticity, and it does not make use of the problematic notion of intuition either. It just relies on a garden-variety type of cognitive process: reasoning. Of course, many details are left to future work. But that seems to be a promising first-step towards the required account of logical knowledge.

\section{References}

BALCERAK JACKSON, Magdalena; BALCERAK JACKSON, Brendan. "Reasoning as a source of justification". Philosophical Studies, 164, 1 (2013), p. 113-126.

BENACERRAF, Paul. "Mathematical Truth". The Journal of Philosophy, 70, 19 (1973), p. 661-679.

BOGHOSSIAN, Paul. "Analyticity Reconsidered". Noûs, 30 (1996), p. 360-391.

BOOLE, George. An Investigation of the Laws of Thought. Cambridge: MacMillan, 1854.

DEVITT, Michael.'There Is No A Priori". In: M. Steup, J. Turri; E. Sosa (eds.). Contemporary Debates in Epistemology, Malden MA: Wiley-Blackwell, 2014. p. 185-194.

DOGRAMACI, Sinan. "Reasoning Without Blinders: A Reply to Valaris". Mind, 125, 499 (2016), p. 889-893.

GOLDMAN, Alvin. "What Is Justified Belief?". In: G. S. Pappas (ed.). Justification and Knowledge, Dordrecht: Reidel, (1979). p. 1-25.

QUINE WILLIAMSON, Timothy. The Philosophy of Philosophy. Malden MA: Blackwell Publishing, 2007.

\section{Endereço postal:}

Ludwig-Maximilians-Universität München

Fakultät für Philosophie, Wissenschaftstheorie und Religionswissenschaft

Munich Center for Mathematical Philosophy

Geschwister-Scholl-Platz 1

D-80539 München

Data de recebimento: $13-10-2016$

Data de aceite: 15-10-2016 